\title{
Protective effects of repeated short sprints in exercise-induced asthma
}

\author{
ROBERT P SCHNALL AND LOUIS I LANDAU \\ From the Department of Thoracic Medicine, Royal Children's Hospital, Melbourne, Australia
}

ABSTRACT Many asthmatic patients demonstrate bronchial lability with a six-minute period of exercise, which is characterised by an initial bronchodilatation followed by bronchoconstriction. 0 This early bronchodilatation response has been further analysed by investigation of the effects ${ }_{-}$ of repeated 30-second sprints before and after a six-minute run. It was found that these repeatedz short sprints did not induce bronchoconstriction, resulted in less bronchoconstriction after $a_{\mathbb{S}}^{O}$ subsequent six-minute run, and caused bronchodilatation if exercise-induced bronchoconstriction $\frac{\mathbb{D}}{\sigma}$ was present. It is postulated that this effect may be related to an increase in circulating catecho-吕 lamines or altered vagal-sympathetic balance.

Exercise-induced bronchoconstriction (EIB) is a well-recognised phenomenon in many individuals with asthma. Two phases in the response to exercise have been documented. Initially there is a short period of bronchodilatation and, provided the exercise is of sufficient intensity and duration, this is followed by a period of bronchoconstriction which is both more prolonged and more pronounced than the earlier bronchodilatation. ${ }^{12}$

Despite the recognition of the dual effects of exercise, most studies have examined the period of bronchoconstriction and have sought possible

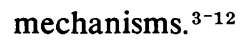

The present investigation was undertaken to examine the phenomenon of bronchodilatation produced by short periods of running in subjects in whom EIB had occurred after a standard exercise test. It was considered that the bronchodilatation produced by short periods of running might exert a modifying influence on the response to more prolonged exercise and that this could have clinical application.

\section{Methods}

SUBJECTS

Four males and two females aged from 12 to 31 years took part in the study. They all had a history of EIB and this had been confirmed by previous laboratory studies. They were free of symptoms of

Address for reprint requests: Dr LI Landau, Department of Thoracic Medicine, Royal Children's Hospital, Parkville, Victoria 3052, Australia. asthma or respiratory infection at the time of the study and had received no bronchodilator or sodium cromoglycate therapy for at least eight. hours before performing the tests. None was re-市 ceiving long-acting xanthine or steroid therapy.

\section{EXPERIMENTAL DESIGN}

A series of three tests was performed by each individual (fig 1). In test 1 , subjects ran twice on a treadmill for six minutes with a 49 -minute break between the periods (runs A and B). In test 2, the first six-minute period of running (run $C$ ) was:followed after 10 minutes by seven short runs each 3 . lasting 30 seconds and separated by breaks of $2.5 \AA$ minutes. A second period of six minutes running? (run $D$ ) began 20 minutes after completion of theo short runs, this being 49 minutes after cessation $D$ of the first long run. In test 3 , the seven periodso of running were completed 20 minutes before one period of six minutes of running (run E).

Tests were performed on separate days in ran- $N$ dom order and all tests were completed within N four weeks.

PULMONARY FUNCTION MEASUREMENTS

Pulmonary function measurements were made $\stackrel{\oplus}{?}$ before and after running as indicated in fig 1. Peak 7 expiratory flow rate (PEFR) was measured usingo a Wright Peak Flow Meter (Airmed Ltd). Forcedo vital capacity (FVC), forced expiratory volume in $\stackrel{\mathbb{Q}}{\Omega}$ one second $\left(\mathrm{FEV}_{1}\right)$, and forced expiratory flow be- $\overline{0}$ tween 25 and $75 \%$ of vital capacity $\left(\mathrm{FEF}_{25-75 \%}\right)_{\Omega}$ 


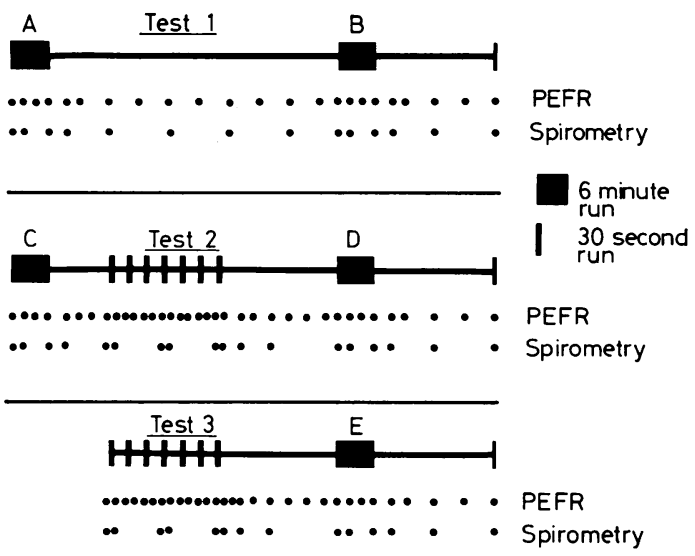

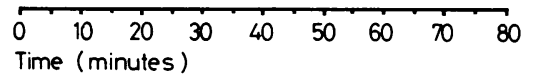

Fig 1 Programme of the running activities and pulmonary function measurements in the series of three tests. $A=$ standard six-minute exercise at start of test $1 ; B=$ standard six-minute exercise 49 minutes after initial six-minute run; $C=$ standard six-minute run at start of test $2 ; D=$ standard six-minute run preceded 49 minutes before by a six-minute run and 20 minutes before by sprints; $E=$ standard six-minute run preceded by sprints.

were measured with a water-sealed spirometer (WE Collins Inc).

Baseline results were taken as the best of three measurements provided individual measurements agreed within $10 \%$. All other spirometric measurements were taken as the best of two so that the forced expiratory manoeuvre could be kept within reasonable limits. ${ }^{13}$

\section{TREADMILL RUNNING}

Subjects ran on a treadmill (Avionics Pty Ltd) which was set at $10 \%$ grade. The treadmill speed was determined on the basis of the subject's exercise and sporting history and an estimate of the workload necessary to achieve a heart rate of 180 BPM. ${ }^{14}$ During the short runs, the treadmill speed was increased to about $120-130 \%$ of that used for the six-minute run.

The tests were performed under constant environmental conditions in a room in which the temperature ranged from $21^{\circ} \mathrm{C}$ to $23 \cdot 5^{\circ} \mathrm{C}$, barometric pressure was $746 \mathrm{mmHg}$ to $759 \mathrm{mmHg}$, and relative humidity usually recorded at $55 \%$.

\section{STATISTICAL METHODS}

Comparison of post-exercise falls from baseline values was made by Student's $t$ test for paired data. Regressions were calculated by the method of least squares.

\section{Results}

Mean baseline values for PEFR, $\mathrm{FEV}_{1}, \mathrm{FEF}_{25-75 \%}$, and FVC for the six subjects are given in table 1. There was no significant difference in baseline values before the three tests. A heart rate of greater than 180 beats per minute was achieved during the five six-minute runs and was not significantly different between runs.

Table 1 Basal pulmonary function measurements before the start of the three tests, expressed as means and standard deviations of absolute values and percentage predicted normal for height and sex

\begin{tabular}{|c|c|c|c|c|}
\hline & & Test 1 & Test 2 & Test 3 \\
\hline $\begin{array}{l}\text { PEFR } \\
(1 / \mathrm{min})\end{array}$ & $\begin{array}{l}\text { Mean } \\
\text { SD } \\
\% \text { predicted }\end{array}$ & $\begin{array}{r}423 \cdot 7 \\
127 \cdot 9 \\
91 \cdot 7\end{array}$ & $\begin{array}{r}428 \cdot 7 \\
97 \cdot 5 \\
92 \cdot 9\end{array}$ & $\begin{array}{r}438 \cdot 3 \\
133 \cdot 2 \\
94 \cdot 9\end{array}$ \\
\hline $\begin{array}{l}\text { FEV }_{1} \\
(1 \text { BTPS})\end{array}$ & $\begin{array}{l}\text { Mean } \\
\text { SD } \\
\% \text { predicted }\end{array}$ & $\begin{array}{l}2 \cdot 70 \\
0 \cdot 71 \\
84 \cdot 1\end{array}$ & $\begin{array}{c}2 \cdot 81 \\
0 \cdot 74 \\
87 \cdot 5\end{array}$ & $\begin{array}{r}2 \cdot 81 \\
0.89 \\
87 \cdot 5\end{array}$ \\
\hline $\begin{array}{l}\text { FEF.25-75 } \\
\text { (1/s BTPS) }\end{array}$ & $\begin{array}{l}\text { Mean } \\
\text { SD } \\
\% \text { predicted }\end{array}$ & $\begin{array}{l}2 \cdot 27 \\
0 \cdot 74 \\
58 \cdot 5\end{array}$ & $\begin{array}{r}2.52 \\
1.05 \\
64.9\end{array}$ & $\begin{array}{c}2.56 \\
0.93 \\
66.6\end{array}$ \\
\hline $\begin{array}{l}\text { FVC } \\
\text { (1 BTPS) }\end{array}$ & $\begin{array}{l}\text { Mean } \\
\text { SD } \\
\% \text { predicted }\end{array}$ & $\begin{array}{c}3.76 \\
0.91 \\
96.9\end{array}$ & $\begin{array}{r}3 \cdot 78 \\
0 \cdot 89 \\
97 \cdot 4\end{array}$ & $\begin{array}{r}3 \cdot 91 \\
1 \cdot 05 \\
100 \cdot 8\end{array}$ \\
\hline
\end{tabular}

The time course of the mean PEFR in the three tests is shown in fig 2 . It will be noted that the falls in PEFR after the second six-minute exercise in test 2 (after a previous six-minute run and a series of short runs) was less than that which occurred after the second six-minute exercise in test 1 (after the initial six-minute run only). The smallest fall in PEFR was seen after the sixminute exercise in test 3 (after a previous series of short runs only).

In fig 3 the mean and one SEM of the maximum post-exercise falls in PEFR, $\mathrm{FEV}_{1}$, and $\mathrm{FEF}_{25_{-}-75}$ after the five, six-minute runs are shown. The changes in the three tests of airways obstruction were similar but were most marked in $\mathrm{FEV}_{1}$. Statistical analysis (table 2) indicated significantly smaller falls in PEFR $(p<0.02)$, FEV $_{1}(p<0.05)$, and $\mathrm{FEF}_{25-75 \%}(\mathrm{p}<0.05)$ after the six-minute run of test 3 ( $\mathrm{E}$, when preceded by short runs alone), than after the first six-minute exercise of test 1 (A, no preceding runs). Similarly the falls in PEFR $(\mathrm{p}<0.05)$ and $F E V_{1}(\mathrm{p}<0.05)$ but not in $\mathrm{FEF}_{25-75 \%}$ $(p>0 \cdot 25)$, were significantly less after the second six-minute exercise of test $2(\mathrm{D}$, after both a previous six-minute run and then short runs) than after the second six-minute run of test 1 (B, after a previous six-minute run but no short runs). 


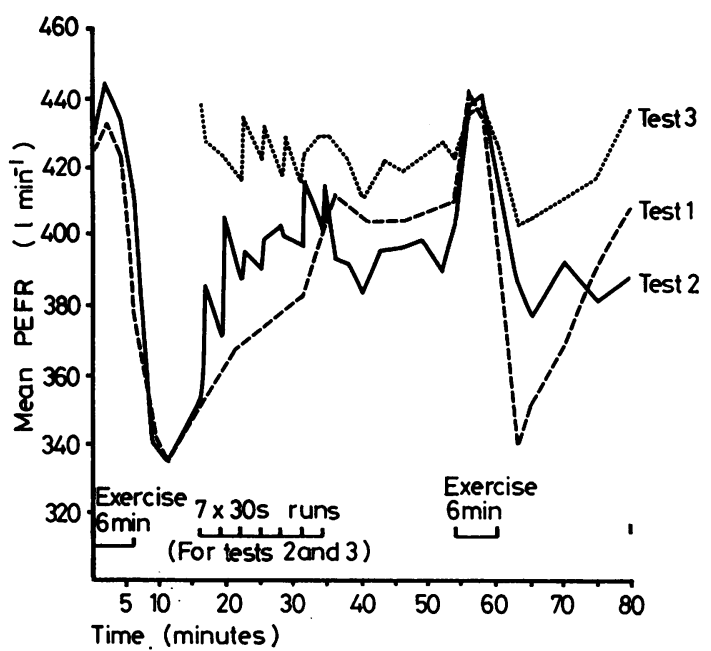

Fig 2 Mean values of PEFR measured during each test.

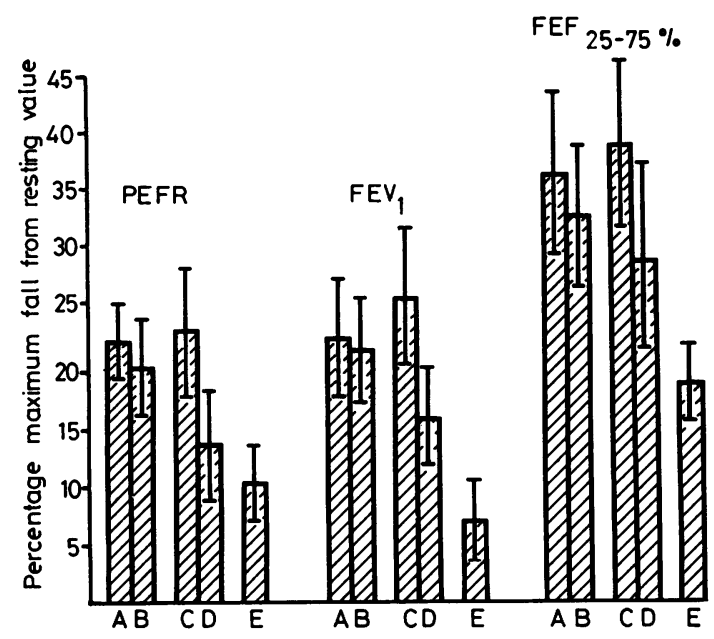

Fig 3 Histogram depicting the mean maximal post-exercise falls $\pm 1 S E M$ in PEFR, FEV ${ }_{1}$, and $F_{E F} F_{25-75 \%}$ after the five six-minute runs. Falls were calculated as percentage change from basal values before the start of the tests. Runs labelled $A$ to $E$ as in fig 1 .

While there was not a statistically significant difference between the falls in PEFR, FEV , and FF, $F_{25-75 \%}$ after the six-minute exercise of test 3 (E, preceded by short runs alone) than after the second six-minute exercise of test 2 (D, preceded by a six-minute and a series of short runs), the mean fall in all three tests was less after the exercise preceded by the short runs alone.
Table 2 Mean maximal post-exercise falls $( \pm 1$ SEM) from baseline values of PEFR, FEV after a standard six-minute exercise challenge $(A)$, and after the six-minute run preceded by seven 30-second sprints

\begin{tabular}{|c|c|c|c|}
\hline & $A$ & $\boldsymbol{E}$ & ${ }^{*} p$ \\
\hline PEFR & $22.8 \% \pm 3.3 \%$ & $10 \cdot 4 \% \pm 3 \cdot 1 \%$ & $<0.02$ \\
\hline $\mathrm{FEV}_{1}$ & $23.0 \% \pm 5 \cdot 2 \%$ & $6.9 \% \pm 3.3 \%$ & $<0.05$ \\
\hline FEF $_{25-75} \%$ & $37.3 \% \pm 7.0 \%$ & $18.9 \% \pm 3.1 \%$ & $<0.05$ \\
\hline
\end{tabular}

If PEFR during the seven short runs after sixoo minutes of running is compared with PEFR aftero six minutes of running without further short runs, $\overrightarrow{-}$ it will be noted that each short run produced a transient improvement in PEFR (fig 4), which was in proportion to the degree of bronchoconstriction present immediately before first sprint. Similax but smaller changes were seen in $\mathrm{FEV}_{1}$ and $\mathrm{FEF}_{25-75 \%}$. Figure 5 shows the relationship be:o tween the increase in flow rate associated with the 30-second sprints and the level of bronchocono striction present at the beginning of the sprint Lines of best fit for the data for the first and second of the seven sprints are shown. Correlation coefficients were 0.67 and $0.82(p<0.05)$ for the first and second sprint data respectively.

One subject developed some bronchoconstric tion during the seven short runs of test 3 and this

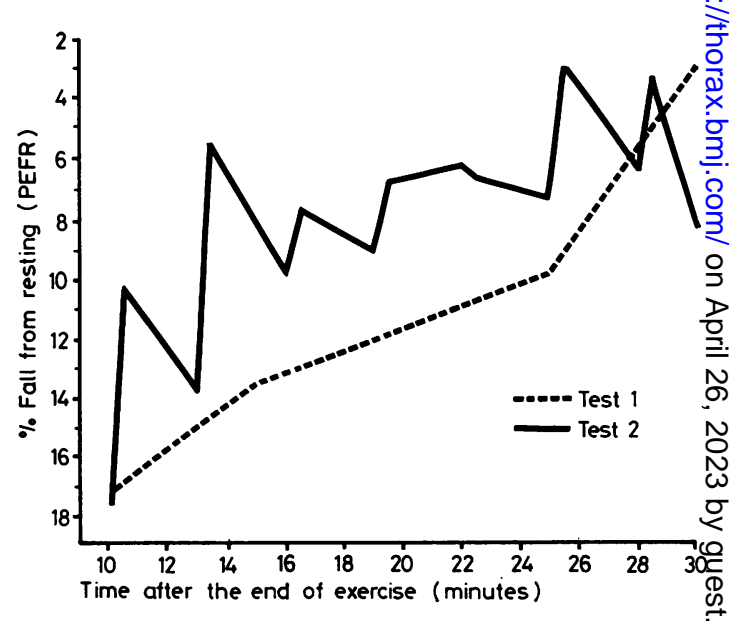

Fig 4 Peak expiratory flow rate during induced bronchoconstriction in test 1 where subjects rested after the initial six-minute run and in test 2 where seven 30 -second sprints with 2.5 minutes separation were conducted after the six-minute run. Measurements were taken between 10 and 30 minutes after the end of the initial six-minute run. 


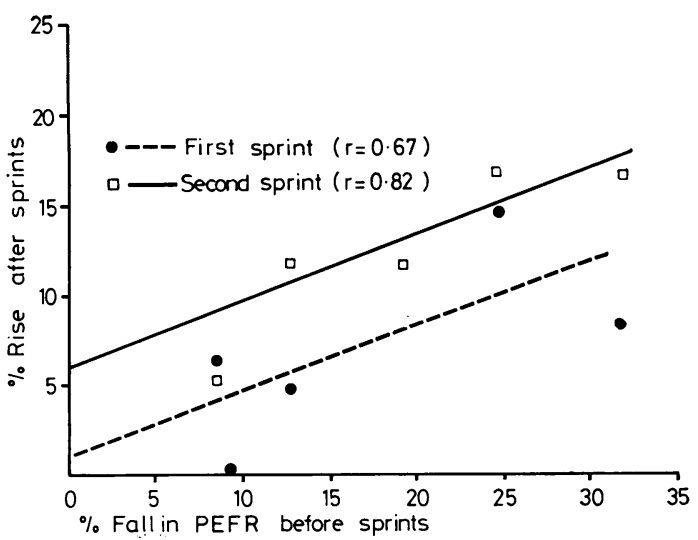

Fig 5 Relationship between the percentage fall from the baseline value of PEFR at 10 minutes after the end of the first six-minute exercise of test 2 and the rises in PEFR immediately after the first and second sprints. All measurements are expressed as percentage baseline PEFR. Lines of best fit were determined by the method of least squares.

continued during the subsequent rest period. The other five subjects did not show significant changes during either the seven short runs or the subsequent rest period.

\section{Discussion}

The changes in lung function that occur as a result of an appropriate exercise stimulus are characteristically biphasic. During the early part of a six-minute run there is a small but definite increase in flow rates that is more marked with greater resting levels of airway obstruction. ${ }^{1}$ After about four minutes of running, the dilatation gives way to bronchoconstriction and flow rates start to fall. This represents the onset of EIB. ${ }^{14}$

Proposed mechanisms for exercise-induced bronchoconstriction have included lactic acidosis, ${ }^{10}$ hypocapnia, ${ }^{14}$ metabolic imbalance, mediator release, ${ }^{3414}$ imbalance of components of the autonomic nervous system, ${ }^{516}$ activation of pharyngeal receptors, ${ }^{8}$ carotid body stimulation, ${ }^{17}$ and airway cooling. ${ }^{7}$

The early bronchodilatation is thought to be a manifestation of an increased sympatho-adrenal drive. ${ }^{18}$ This increased sympathetic activity may modify the response of an asthmatic to exercise by action at three sites. Bronchial smooth muscle tissue may be directly affected by the stimulation of $\beta_{2}$ receptors resulting in an increased intracellular level of cyclic AMP and relaxation of bronchial smooth muscle. An elevation of the plasma titre of catecholamines may stabilise the mast cell membrane thus inhibiting the release of bronchoconstricting mediators. ${ }^{19}$ Catecholamines may also inhibit cholinergic discharges which produce bronchoconstriction by inhibiting the release of acetylcholine from postganglionic nerve endings in bronchial smooth muscle tissue. ${ }^{20}$ These latter effects have been observed in vitro, after the exogenous addition of catecholamines.

The reason for the diminished bronchoconstrictor response to repeated exercise is not clear. Tachyphylaxis has been observed when two bronchoconstricting exercises are performed less than two hours apart. ${ }^{3414}$ In this study tachyphylaxis was seen after a potentially bronchoconstricting exercise after previous nonbronchoconstricting sprints. A depletion in stores of mediators capable of producing bronchoconstriction has been suggested as responsible for tachyphylaxis. ${ }^{34}$ It is unlikely that there would be less depletion of mediators after a stress run and short runs than after short runs alone. Protection should have been greater with the combined manoeuvre if this theory was likely. The bronchial smooth muscle may have become refractory to repeated stimulation. However, since smooth muscle does not appear to become refractory to repeated challenge with histamine, ${ }^{21}$ this would suggest that refractoriness at the smooth muscle levels is unlikely to account for the phenomena observed in this study.

Altered vagal or sympathetic tone may be responsible for relative protection from EIB. The components of the autonomic nervous system may act directly on bronchial smooth muscle, on irritant receptors or via inhibition of release of bronchoconstricting mediators from mast cells. Alternatively, the effects may be a result of sympathetic drive caused by increased circulating catecholamines which may inhibit both mediator release and cholinergic discharge.

Although lactic acidaemia is clearly not a prime factor in EIB, ${ }^{11}$ a warm-up effect of short runs may help improve circulation to the appropriate muscles and reduce anaerobic respiration during the run that provoked asthma. These short sprints may also have provided sufficient warm-up for the subjects to exercise more efficiently, with greater oxygen extraction and therefore lower ventilation during subsequent runs.

The improvement in the PEFR when repeated short runs were performed during a bronchoconstrictive phase may have been the result of increased sympathetic drive either directly or through catecholamine release. Inhibition of mediator release would not produce bronchodilatation. 
Inhibition of the bronchoconstrictor effect of vagal nerve activity may result in relative bronchodilatation through inhibition of the cholinergic drive.

The relative increase in PEFR with a short run was shown to be proportional to the relative severity of bronchoconstriction at the beginning of the run and this is in agreement with the report by Jones $e t a^{1}$ of a correlation between the magnitude of the bronchodilatation seen early in an exercise test and the degree of airways obstruction before the start of exercise.

The response of asthmatics to exercise has always been variable and suggestive of a heterogeneous response to this stress. Thus, while several mechanisms have been proposed, their relative contributions are difficult to evaluate. Since the effects of the warm-up could be working at a number of sites it is possible that the protective effect could be the result of differing mechanisms in individuals according to the relative contributions of these mechanisms in producing their EIB. Further studies of the relationship between the bronchoconstricting and bronchodilating phenomena may help elucidate the mechanisms involved.

This study demonstrates that repeated short runs minimise the bronchoconstricting effect of subsequent exercise stress and have a bronchodilating effect on previous EIB. These observations suggest that an exercise programme could be devised for asthmatics which will enable increased physical activity with less risk of bronchoconstriction. They provide objective evidence to support the impression that asthmatics can cope better with repeated short duration activities and that a warm-up period may be beneficial in allaying the effects of more prolonged periods of exercise.

This work was supported by the National Health and Medical Research Council of Australia.

\section{References}

1 Jones RS, Buston MH, Wharton MJ. The effect of exercise on ventilatory function in the child with asthma. Br J Dis Chest 1962; 56:78-86.

2 Jones RS, Wharton MJ, Buston MH. The place of physical exercise and bronchodilator drugs in the assessment of the asthmatic child. Arch Dis Child 1963; 38:539-45.

3 McNeill RS, Nairn JR, Millar JS, Ingram CG. Exercise induced asthma. $Q J$ Med 1966; 35:55-67.

4 Edmunds AT, Tooley M, Godfrey S. The refractory period after exercise-induced asthma: its duration and relation to the severity of exercise.
Am Rev Respir Dis 1978; 117:247-54.

5 Simonsson BOG, Skoogh BE, Ekstrom-Jodal B⿳亠丷厂 Exercise-induced airways constriction. Thora $\overrightarrow{\mathrm{D}}$ 1972; 27:169-80.

6 Chan-Yeung, MW, Vyas MN, Grzybowski Sक़̣ Exercise-induced asthma. Am Rev Respir Di $\overrightarrow{\mathscr{S}}$ 1971; 104:915-23.

7 Deal EC Jr, McFadden ER Jr, Ingram RH Jr $\overrightarrow{\vec{\omega}}$ James JJ. Hyperpnea and heat flux: initial res action sequence in exercise-induced asthma. $\stackrel{\overrightarrow{2}}{\vec{x}}$ Appl Physiol 1979; 46:476-83.

8 McNally JF Jr, Enright P, Hirsch JE, Souhrada JF. The attenuation of exercise-induced bronchocontriction by oropharyngeal anaesthesia. $A m p$ Rev Respir Dis 1979; 119:247-52.

9 Middleton E Jr. Airway smooth muscle if exercise-induced bronchospasm: some speculations. Pediatrics 1975; 56:944-7.

10 Seaton A, Davies G, Gaziano D, Hughes RO Exercise-induced asthma. Br Med J 1969; 3:556-8

11 McFadden ER Jr, Soter NA. A search for chemio cal mediators of immediate hypersensitivity and humoral factors in the pathogenesis of exercise $\overrightarrow{0}$ induced asthma. In Lichtenstein LM, Austen KFO Simon AS (eds). Asthma physiology, immuno:pharmacology, and treatment. Second Intero national Symposium. New York: Academic Press 1977; 351-64.

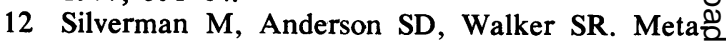
bolic changes preceding exercise-induced broncho $\frac{1}{8}$ constriction. Br Med J 1972; 1:207-9.

13 Orehek J, Gayrard P, Grimand C, Charpin J⿳⺈ Effect of maximal respiratory manoeuvres on bronchial sensitivity of asthmatic patients as com pared to normal people. $\mathrm{Br}$ Med J 1975; 1:123-5:

14 Godfrey $S$. Exercise-induced asthma-clinical physiological, and therapeutic implications. Allergy Clin Immunol 1975; 56:1-17.

15 Anderson SD, Seale JP, Rozea P, Bandler L Theobald G, Lindsay DA. Inhaled and oral sal butamol in exercise-induced asthma. Am Rev Respir Dis 1976; 114:493-500.

16 Editorial. Non-allergic provocation of asthma.o Lancet 1975; 2:691-2.

17 Schiffman PL, Ryan A, Whipp B, Hansen JE: Wasserman K. Hyperoxic attenuation of exercise induced bronchospasm in asthmatics. J Clin Inves 1979; 63:30-7.

18 Godfrey S. Exercise-induced asthma. Allergy

19 Lichtenstein LM, Margolis S. Histamine release in vitro: inhibition by catecholamines and methyl xanthines. Science 1968; 161:902-3.

20 Vermeire PA, Vanhoutte PM. Inhibitory effects of catecholamines in isolated canine bronchial smooth muscle. J Appl Physiol 1979; 46:787-91. 후

21 Anderson SD, Schoeffel RE, Lindsay DA. Thed effects of repeated exercise and histamine chal- $\frac{O}{D}$ lenge in patients with asthma (abstract) Aust $N Z \propto$ J Med 1979; 9:481. 